\title{
The increasing prevalence of Crohn's disease in industrialized societies: The price of progress?
}

\author{
Ron W Wells MSc, Michael G Blennerhassett PhD
}

RW Wells, MG Blennerhassett. The increasing prevalence of Crohn's disease in industrialized societies: The price of progress? Can J Gastroenterol 2005;19(2):89-95.

Crohn's disease (CD) is an idiopathic inflammatory condition of the gastrointestinal system. While inflammation can activate one of a number of specific branches of the immune system, CD promotes a T helper cell type 1 (Th1) profile. The prospect that CD is a form of Th1-dominant autoimmune disease is gaining acceptance, with support from the current use of immunosuppressants. Recently, convincing evidence that the various branches of the immune system have the ability to keep each other in check has suggested that the Th1 profile of CD may stem from a greatly reduced T helper cell type 2 (Th2) immune response. A strong Th2 immune response is a characteristic of the once prevalent enteric parasitic diseases, now nearly eradicated from industrial society. This has led to the acceptance of a hygiene hypothesis, which suggests that the inverse relationship between $C D$ and the level of a society's industrialization is, in fact, causal - that the lack of parasitic infections causes a weakened systemic Th2 cytokine profile, leading to elevated Th1 cytokines and, ultimately, the development of spontaneous Th1-mediated diseases such as CD. Supporting this, it has been recently demonstrated that an experimentally-induced Th2 response can help moderate Th1dominant events in both animal and human studies. Based on this recent and convincing work, the present review focuses on the role of immunoregulation in the development of $\mathrm{CD}$, with particular emphasis on the potential use of Th2-promoting agents (such as helminths or cytokines) as therapeutics in the treatment or prevention of CD.

Key Words: Autoimmune disease; Crohn's disease; Helminth; Hygiene hypothesis; Immunoregulation; Th1/Th2

\section{La prévalence croissante de maladie de Crohn dans les sociétés industrialisées : Le prix du progrès ?}

La maladie de Crohn (MC) est une pathologie inflammatoire idiopathique du système gastro-intestinal. L'inflammation peut activer l'une de plusieurs ramifications précises du système immunitaire, et la $\mathrm{MC}$ favorise le profil de lymphocyte T auxiliaire de type 1 (LT1). L'idée que la MC est une forme de maladie auto-immune à LT1 dominant est de plus en plus acceptée et est appuyée par le recours actuel aux immunosuppresseurs. Récemment, des données probantes selon lesquelles les diverses ramifications du système immunitaire peuvent se contenir les unes les autres indiquent que le profil LT1 de la MC proviendrait d'une réponse immunitaire très affaiblie d'un lymphocyte $\mathrm{T}$ auxiliaire de type 2 (LT2). Une puissante réponse immunitaire LT2 est caractéristique des maladies parasitaires entériques autrefois prévalentes et quasiment éradiquées de la société industrielle. Ce constat entraîne l'acceptation d'une hypothèse de l'hygiène, qui laisse supposer que le lien inversement proportionnel entre la MC et le taux d'industrialisation d'une société est, en fait, causal, c'està-dire que l'absence d'infections parasitaires provoque un profil de cytokines LT2 systémiques affaiblies qui suscite la présence de cytokines LT1 élevées et, au bout du compte, l'apparition de maladies à médiation LT1 spontanées, telles que la MC. Pour étayer cette hypothèse, il a récemment été démontré qu'une réponse LT2 induite en milieu expérimental peut contribuer à modérer les événements LT1 dominants dans le cadre d'études à la fois auprès d'animaux et d'humains. D'après ces travaux récents et convaincants, la présente analyse porte sur le rôle de l'immunorégulation dans l'apparition de la MC, et surtout sur le recours potentiel à des agents promoteurs de LT2 (tels que les helminthes et les cytokines) comme produits thérapeutiques pour prévenir la MC.
$\mathrm{C}^{\mathrm{r}}$ rohn's disease $(\mathrm{CD})$ is an increasingly common, idiopathic condition of intestinal inflammation, causing diarrhea and pain during periods of exacerbation, resulting in substantial morbidity. While many theories on the etiology of CD exist (for review see [1]), the exact factors that lead to the development of this disease remain to be elucidated. Nevertheless, there is strong evidence that an immunological imbalance contributes to the development and onset of this disease (2). Furthermore, epidemiological data indicate an inverse relationship between $\mathrm{CD}$ and helminth gut infections, with $\mathrm{CD}$ appearing as a disease of industrialized countries $(3,4)$. It is well accepted that specific antigens will promote the production of specific cytokines and, as such, the immune response can be divided into different subsets, termed T helper cell types 1 and
2 (Th1 and Th2, respectively). Recently, it was demonstrated that the development of a Th2-dominant profile could attenuate a previously established Th1-dominant colitis (5). Combined, recent results suggest that human $\mathrm{CD}$ may result from an imbalance between the different subsets of the immune response. We hope to present a logical and persuasive argument in support of a causative relationship between industrialization, deworming and CD. However, there is still a great degree of controversy surrounding the deworming theory, and a number of other possible explanations exist for the increased prevalence of $\mathrm{CD}$ in industrialized countries, such as exposure to measles virus (6), the cold chain hypothesis (7) and poor dietary habits (8), and these will also be briefly addressed.

Gastrointestinal Diseases Research Unit, Hotel Dieu Hospital, Queen's University, Kingston, Ontario

Correspondence: Dr Michael G Blennerhassett, Gastrointestinal Diseases Research Unit, Hotel Dieu Hospital, 166 Brock Street, Kingston,

Ontario K7L 5G2. Telephone 613-544-3400 ext 2008, fax 613-544-3114, e-mail mblen@meds.queensu.ca

Received for publication March 19, 2004. Accepted September 23, 2004 


\section{TABLE 1}

\section{The hygiene hypothesis}

1. Intestinal organisms are important for shaping not only the local intestinal immune system, but also systemic immune responses.

2. The increasing hygienic lifestyle in industrialized society minimizes natural surroundings that once promoted the adaptation of immune systems, and now provide an intestinal environment far different from that of previous generations.

3. This difference is leading to the emergence of various autoimmune and other immunological diseases.

4. Loss of helminth colonization and the unique influence of these animals on the immune response are major factors contributing to the development of these diseases.

Adapted from reference 3

\section{IMMUNODYSREGULATION AND CD}

Due to the nature of the gastrointestinal tract, the environment comes in direct contact with the luminal surface and, thus, ingested substances can act as potential antigens. However, despite the chronic presence of antigens in the semipermeable intestinal lumen, there is not a significant elevation in inflammatory mediators. For example, after drinking cow's milk, intact milk proteins can be detected in the blood of healthy individuals at immunogenic levels $(1 \mathrm{ng} / \mathrm{mL}$ to $10 \mathrm{ng} / \mathrm{mL}$ ) yet, despite this, there is no significant systemic immune response (9). It has been suggested that the ingestion of specific antigens can elicit a local immune response in the luminal mucosa, primarily due to the activation or inhibition of specific regulatory and Th cells $(10,11)$. The local activation of these Th cells results in secretion of anti-inflammatory cytokines, such as interleukin (IL)-4, IL-10 and transforming growth factor-beta, which initiate systemic immunity to these ingested antigens and result in in oral tolerance $(12,13)$. Therefore, under normal conditions, the maintenance of a healthy intestinal physiology requires the presence of a delicate balance between immunoreactivity and immunotolerance.

Nevertheless, oral tolerance does not always work properly and, occasionally, an antigen that would be normally tolerated (antigenic acceptance) can result in a profound and serious inflammatory response. For example, some individuals respond to the ingestion of cow's milk proteins with a strong Th cell response that result in severe intestinal inflammation (14). Recent evidence suggests that CD can also include aspects of improper immunological response to dietary antigens or resident microbial flora $(1,15)$. Further support for this hypothesis is that current treatment for CD includes immunosuppressive therapy (16). This approach addresses all aspects of inflammation in a nonspecific manner, and the exact cause of CD has yet to be elucidated.

\section{THE HYGIENE HYPOTHESIS}

Current epidemiological data have demonstrated the existence of a positive correlation between the incidence of diseases involving a component of an immune imbalance (such as inflammatory bowel disease [IBD]) and the level of industrialization, thus providing a possible environmental explanation $(17,18)$. In the past 60 years, primarily as a direct result of increased levels of sanitation and the treatment of water, industrialized countries have dramatically decreased the occurrence of helminth infections, with only $0.5 \%$ of the industrialized population showing recent infection (3). However, the incidence of CD in these countries has increased substantially over the past 40 years, affecting approximately $0.1 \%$ of the industrialized population $(1,3,19)$. In contrast, in developing countries where overcrowding and poor sanitation are serious concerns, helminth infections are endemic and diseases such as CD are virtually nonexistent $(20,21)$. Furthermore, $C D$ is less frequent in people with jobs involving increased exposure to substandard sanitization (22). Taken together, these statistics have lead to the development of the 'hygiene hypothesis' (Table 1) $(3,23)$, which proposes that exposure to parasites contributes to the maintenance of a healthy immunoregulatory balance in the intestine. Thus, the absence of intestinal parasites tends to promote, or permit, the development of CD in genetically susceptible individuals.

A recent review by Hugot et al (7) explores the alternative mechanism of an increased presence of a potential pathogen as a possible factor in the development of CD. This 'cold chain' hypothesis postulates that the advent of ubiquitous refrigeration in modern society allows psychrotrophic bacteria (eg, Mycobacterium, Listeria and Yersinia) to persist as common pathogens (albeit at low levels) in foods at refrigerator temperatures. In industrialized countries, genetically predisposed individuals would be repeatedly exposed to these pathogens and CD might thus develop. However, the problem with this hypothesis is that it is difficult to separate the relative role of other components, such as increased sanitation and housing, which are all common elements in industrialized society. In support of the hygiene hypothesis, it has been observed that individuals emigrating from areas with high levels of helminth infections do not develop CD while their descendents living in industrialized countries do (24). If refrigeration were the causative factor, CD would be seen in the emigrating individuals at levels equal to their offspring, which is not the case. There is the possibility that exposure to these psychrotrophic bacteria during childhood is needed for the future development of $\mathrm{CD}$, but that hypothesis needs to be thoroughly examined in a search for supportive evidence.

Another possible etiological factor in the development of $\mathrm{CD}$ is the poor dietary habits that are found in industrialized society. In a recent review by Cashman and Shanahan (8), the increased ingestion of refined sugar and decreased consumption of fresh produce is suggested as a causative factor in IBD. However, as with refrigeration, if dietary habits were the causative factor, $\mathrm{CD}$ would be seen in the emigrating individuals and their offspring at equal levels, which is not the case. It may be that emigrating individuals stay with a more traditional (nutritionally balanced) diet while their descendents convert to an industrialized, highly processed diet. Clearly, more research into testing these (and other) alternative theories is needed.

While many theories exist on risk factors in the development of CD, based on current literature, the authors feel that the evidence supporting a reduction in helminth infections as the underlying factor in the development of CD is the most convincing single hypothesis, because reintroduction of helminths helps alleviate the severity of intestinal inflammation in animal models and human disease.

THE INTESTINAL INFLAMMATORY RESPONSES Under normal conditions, the presence of foreign intestinal antigens will result in an immunological response through one of either the Th1 or Th2 cells, which exert their biological 
function through the secretion of specific cytokines. The Th1 response is generally involved in the development of cellmediated immunity, while the Th2 response recruits the antibodies needed to neutralize parasitic invaders, such as helminths $(3,4)$. There is ample evidence that CD is a Th1polarized immune response (25-27). For example, studies using CD patients showed high levels of the Th1 cytokines interferongamma (IFN $\gamma$ ) and tumour necrosis factor-alpha, and diminished Th2 cytokines (28). Therefore, it has been postulated that, due to society becoming 'too clean', intestinal immunological responses have been skewed so that there is an imbalance in favour of the Th1 response. Is it possible that this imbalance results in the progression towards the development of intestinal inflammation which, combined with the appropriate polygenic determinants, then progresses to the manifestation of CD?

The development of an immunological response to a particular pathogen relies on the regulated induction of the appropriate and specific set of events that result in the elimination of the invading agent or its toxic products. For example, the neutralization of bacterial toxins requires the production of antibodies, whereas the response to an intracellular virus or parasite requires cell-mediated cytotoxicity (29). These highly specific responses occur through the activation of either a predominately Th1- or Th2-mediated immune response. While the precise mechanism involved in the differentiation of a naïve T cell into a Th1 or Th2 cell has yet to be determined, current evidence suggests that the local cytokine environment present during antigen presentation plays a critical role (30).

It has been proposed that the Th1 and Th2 subsets arise through the differentiation of the Th0 cell, where T lymphocytes locally secrete cytokines, which affect the T cells in an autocrine and paracrine fashion. When the naive Th cell is first exposed to a specific antigen, it begins to secrete IL-2, causing proliferation. As more of these naïve Th cells develop, the population will begin to secrete other cytokines such as IFN $\gamma$, IL-4, IL-10 or IL-13 and, with prolonged antigen exposure, the cytokine profile secreted by the Th cells polarize towards either a Th1 or Th2 phenotype (31).

\section{THE TH1 RESPONSE}

The Th1 response is primarily responsible for cell-mediated functions such as those required for viral infections or intracellular pathogens. During Th cell maturation, the IL-12 and IL-18 released from activated macrophages bind to receptors on the naïve Th cell $(32,33)$ and stimulate the secretion of IFN $\gamma$ through the signal transducers and activators of transcription factor-4 (STAT4) pathway (23). The presence of IFN $\gamma$ results in increased macrophage activity and the production of complement-forming antibodies (4); as well, it acts to enhance antigen presentation and IL-12 production (34). IL-18 increases the synthesis of IFN $\gamma$, producing a positive feedback system (29). Once the Th1 cells mature, they secrete a wide variety of cytokines, with IL-12, IFN $\gamma$, tumour necrosis factoralpha and IL-2 predominating (Figure 1).

IL-12 and IFN $\gamma$ are crucial for the proper development of a Th1 response. Their importance has been demonstrated experimentally in IL-12-/- or IFN $\gamma^{-/}$mice, which do not have the ability to develop a significant Th1 immune response compared with control mice (reviewed in [29]). However, it is the early release of IL-12 at the onset of inflammation that promotes IFN $\gamma$ production and Th1 cell development, while

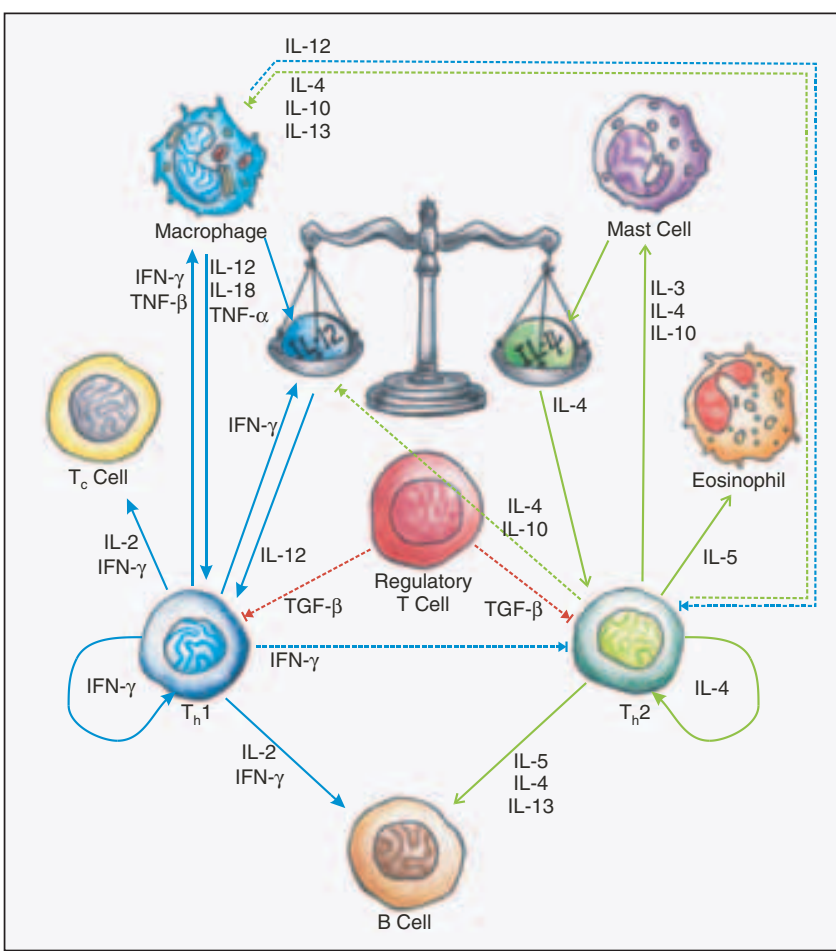

Figure 1) Schematic of the complex interactions between the cytokines of the Thelper cell types 1 and 2 (Th1/Th2) subsets of the immune response. There is a delicate balance between the two subsets of the immune response, where an increase in a specific cytokine can result in profound upregulation of one subset while decreasing the other. All Th1 and Th2 cytokines are represented with blue and green arrows, respectively, and stimulatory and inhibitory effects are represented with solid and broken lines, respectively. IFN- $\gamma$ Interferon-gamma; IL Interleukin; TGF- $\beta$ Transforming growth factor-beta; TNF- $\alpha$ Tumour necrosis factor-alpha

inhibiting the differentiation of Th2 cells $(27,33)$. Furthermore, application of IL-12 neutralizing antibodies prevented the development of 2,4,6-trinitrobenzene sulfonic acid (TNBS)-induced inflammation in mice, whereas anti-IFN $\gamma$ had little effect (35). These observations suggest that IL-12 is the critical cytokine needed for promoting a Th1-mediated immune response, while inhibiting the Th2 branch of the inflammatory response.

\section{THE TH2 RESPONSE}

The Th2 component of an immune response is recruited during helminth infections, which stimulate the activation and differentiation of eosinophils, and initiate the production of immunoglobulin (Ig)M and IgE antibodies (which limit helminth colonization) (4,29). During differentiation, the early presence of IL-4 signalling through the STAT6 pathway induces Th2 maturation (23). The activated Th2 cell will then secrete various cytokines including IL-4, IL-10 and IL-13 (36), which have the ability to augment their own production in a positive feedback circuit (Figure 1) (37). Of these cytokines, IL-10 has a key role in the regulation of the Th2 response. Studies show that administration of IL-10 has the potential to suppress IL-12 production $(32,38)$ and deactivate macrophages $(19,38,39)$. In addition, exogenous IL-10 indirectly downregulates the synthesis of IFN $\gamma$, an important cytokine in the Th1 


\begin{tabular}{lll} 
TABLE 2 \\
Positive and/or negative influential roles of specific \\
cytokines in promoting the development of a T helper cell \\
type $\mathbf{1}$ and $\mathbf{2}$ (Th1/Th2) immune response \\
\hline \multicolumn{1}{l}{ Cytokine } & Th1 & Th2 \\
\hline IL-1 & Excitatory & Inhibitory \\
IL-2 & Excitatory & Inhibitory \\
IL-3 & Excitatory & Excitatory \\
IL-4 & Inhibitory & Excitatory \\
IL-5 & Inhibitory & Excitatory \\
IL-6 & N/A & Excitatory \\
IL-10 & Inhibitory & Excitatory \\
IL-12 & Excitatory & Inhibitory \\
IL-13 & Inhibitory & Excitatory \\
IL-18 & Excitatory & N/A \\
IFN $\gamma$ & Excitatory & Inhibitory \\
TNF $\alpha$ & Excitatory & Inhibitory \\
GM-CSF & Excitatory & Excitatory \\
TGF $\beta$ & Inhibitory & Inhibitory
\end{tabular}

Modified from reference 29. GM-CSF Granulocyte-macrophage colony stimulating factor; IFN $\gamma$ Interferon-gamma; IL Interleukin; N/A Not available; TGF $\beta$ Transforming growth factor-beta; TNF $\alpha$ Tumour necrosis factor-alpha

response $(19,40)$. Therefore, IL-10 appears to have an antiTh1 function, allowing for a stronger Th2 response. Furthermore, in IL-10-/- mice, there was no detectable expression of a population of Th2 cytokines, including IL-4 or IL-13 $(2,38)$. Taken together, these results suggest that IL-10 has a critical role in the development and regulation of a Th2 immune response.

IL-10 also has a potent immunoregulatory and antiinflammatory role. IL-10-/- knockout mice will spontaneously develop IBD unless kept in a germ-free environment (2). Furthermore, treatment of these animals with nonsteroidal anti-inflammatory drugs significantly hastens the development of the colitis (2). Because CD involves the recruitment of a Th1 immune response and IL-10 is a key regulator of the Th2 response, this suggests that an imbalance between these two subsets may lead to the spontaneous development of IBD, namely CD. In addition, it was demonstrated that IL-10-/mice displayed elevated IFN $\gamma$ expression, a key Th1 cytokine (2), which further strengthens the argument for a spontaneous Th1 immunological response in the development of CD. With this in mind, IL-10 trials in CD failed to lead to overwhelming effects, suggesting a degree of redundancy in the Th1 maturation process (41). Furthermore, while IL-10 is upregulated by a Th2-mediated immune response, the simple presence of IL-10 is not a marker for a Th2-mediated immune response. IL-10 is a key regulatory cytokine and it may be that a lack of stimulation (via helminth or other mechanism) leads to a depletion of IL-10, leading to uncontrolled immune function and resulting in the polarization of one branch of the immune system. However, this is speculative and research on this topic is lacking.

Like IL-10, IL-4 exerts an anti-inflammatory effect by restricting damage and promoting repair (42). In addition, evidence suggests that IL-4 is also a key regulatory cytokine for the Th2 response (Figure 1). For example, if exogenous IL-4 is provided at low levels, Th2 cytokine development is favoured over Th1, even in the presence of potent Th1 stimulatory agents such as IL-12 (29). Furthermore, if the actions of IL-4 are eliminated, as in either IL-4 $4^{-/}$or STAT6 ${ }^{-/}$knockout mice, there is poor Th2 cytokine development and reduced eosinophil recruitment (32). Therefore, it appears that several cytokines are critical for the development of a Th2 response and that the Th2 response is likely to be favoured over a Th1 immune response.

\section{CROSSREGULATION OF THE TH1 AND TH2 SUBSETS}

It has been well-established that there is crossregulation of the Th1/Th2 immune responses. Cytokines produced by either subset have two characteristic effects on immunodevelopment: they promote the growth of their subset; and they inhibit the development and activation of the opposite subset (Table 2). For example, activation of a Th2 immune response promotes the production of IL-4 and IL-10, while high levels of IFN $\gamma$, which support Th1 development, will directly suppress the production of these two Th2 cytokines (Figure 1) (43). Conversely, IL-4 will inhibit IL-12, thus decreasing IFN $\gamma$ release and ultimately crossregulating the Th1 response (44). In addition, IL-10 blocks the macrophage accessory cell function required by the Th1 cells but not Th2 cells, further repressing the Th1 response (45). Combined, these results suggest that the presence, even in low levels, of cytokines from a Th2 subset should be capable of crossregulating a more dominant Th1 subset. For example, mild activation of the Th2 subset should produce low level concentrations of Th2 cytokines, which would have the ability to reduce the production and activation of Th1 cytokines. However, in the chronic absence of a Th subset, the other subset has the ability to promote its own development completely unrestricted, such as that observed during $\mathrm{CD}$.

Many of the current models of experimental colitis result in a strong Th1 immune response. For example, administration of dinitrobenzene sulphonic acid $(23,46)$ or TNBS $(5,47,48)$ will produce a severe transmural, Th1-driven colitis, which is considered yo be an excellent model of CD with many similarities to human disease (48). The inflammatory response in these animals can be diminished or even prevented through treatment with IL-10 or IL-4 (49-52), which indicates the presence of a strong influential and potentially therapeutic interaction between these two Th subsets.

\section{WHAT ARE THE CONSEQUENCES OF SPECIFIC TH1/TH2 POLARIZATION?}

The 'hygiene hypothesis' is a current hypothesis that attempts to explain and identify a causative factor in the development of CD (Table 1). This hypothesis states that an imbalance between the Th1/Th2 lineages has developed because of the increased sanitation in industrialized nations (3). This imbalance in favour of the Th1 subset, in combination with a genetic predisposition, likely leads to the development of chronic CD. The idea for an imbalance between the Th1/Th2 subsets is not new. In fact, there are a number of human conditions that are affected by such an immunological imbalance. One example is the development of leprosy, with tuberculoid leprosy developing from a strong Th1 response and lepromatous leprosy from a polarization of the Th2 response (reviewed in [29]). Therefore, taking into consideration historical diseases with Th1/Th2 imbalance, the 
cytokine profile that exists and the epidemiological evidence showing $\mathrm{CD}$ as an industrialized disease, a logical extension has lead to the development of the hygiene hypothesis.

\section{COULD HELMINTH INFECTION BE A TREATMENT FOR IBD?}

While CD has an obvious genetic involvement $(20 \%$ of patients report a family history), the rapid rise in the number of cases exceeds that predicted by genetics alone $(3,53)$. Instead, it may be that alterations in the environment have resulted in the increased risk for developing $\mathrm{CD}$ in genetically predisposed individuals. Further strengthening this argument is the observation that individuals in developing countries do not develop $\mathrm{CD}$ while their descendants, living in industrialized regions, do (24). Therefore, it seems probable that the lack of helminth infections due to increased sanitization in the industrialized countries has led to attenuation of the Th2 response, and this lack of crossregulation has lead to the polarization of the cytokine profile in favour of the Th1 subset.

In these immunopolarized, genetically predisposed individuals, the presence of low level antigens could lead to a rapid Th1 immune response instead of the usual oral tolerance. It has been demonstrated that the level of IFN $\gamma$ induced by ingested antigen is dependent on the antigen dosage. There is a negative correlation with the highest levels of IFN $\gamma$ produced by mice fed low doses of antigen (11). Therefore, it follows that because the ingested antigen levels would be low, susceptible individuals with Th1 polarization could have an extremely vigorous response to these antigens, resulting in development of CD.

In contrast to a decrease in Th2 cytokines leading to the development of CD, it may be that the loss of specific antiinflammatory cytokines predisposes to runaway inflammatory episodes such as CD. Among these, IL-10 is a prominent candidate due to its ability to inhibit the production of allergen-specific IgE (54). A role for parasite-induced hyperimmunoglobulinemia-E in the nonspecific inhibition of immune responses has been proposed, suggesting that reduced immune responsiveness occurs due to blockade of specific antigenic sites. While this is supported by evidence that tropical populations with high IgE titres show reduced atopy, the experimental induction of passive sensitization was unimpaired and convincing evidence is lacking $(55,56)$.

Recently, it was demonstrated that individuals with repeated viral infections (a Th1-mediated immune response) have a predisposition to develop asthma (a Th2-mediated immune response) $(57,58)$. This suggests that initial acute Th1-dominant inflammatory episodes might set events in motion that lead to a later reciprocal Th2 response, but evidence is lacking. While asthma is generally more common in industrial countries, the proposal that parasitic infection protects against asthma is unsupported so far (59). Therefore, it could be that, consequential to the polarization of either a Th1 or Th2 response, there is an inadequate level of the anti-inflammatory cytokines (such as IL-10) needed to help subdue the inflammatory response, and a prolonged or chronic inflammation ensues.

It has been postulated that if a Th2 response were initiated, anti-inflammatory cytokines would help attenuate the Th1dominated inflammation (10). Supporting this hypothesis, administration of helminths into animals before or during chemically induced colitis reduced the severity of the inflammation $(3,5,23,50,60)$, which was correlated with decreased myeloperoxidase activity, mortality and IFN $\gamma$ expression. In contrast, the administration of Th1-inducing agents exacerbated experimental colitis in mice (61). Therefore, in light of the experimental data showing that $\mathrm{CD}$ can be attenuated with helminth treatment and the epidemiological data showing low prevalence of $\mathrm{CD}$ in populations with high levels of helminth infections, it can be postulated that Th2 therapy will help alleviate $\mathrm{CD}$.

\section{ARE INVESTIGATORS ON THE RIGHT TRACK?}

A decade ago, Ekbom et al (6) demonstrated a positive correlation between in utero exposure to the measles virus and the future development of $\mathrm{CD}$. While the data presented by Ekbom were convincing, and therefore could persuade many individuals into believing that the measles virus was a causative factor, a large body of evidence now suggests that this, in fact, is not the case (62-64). Clearly, discrimination among alternative hypotheses is a critical part of the development of understanding, and the hygiene hypothesis must survive similar scrutiny. This will be both at the general level of an association of increased Th1-dominant disease with specifically parasite-free conditions, as well as the identification of a mechanism that can eventually be held responsible. Indeed, current data is very convincing in that helminth administration can help alleviate a Th1-dominant intestinal inflammation, and perhaps the first level of assessment has already been passed successfully.

\section{FUTURE OF CD THERAPY}

$\mathrm{CD}$ is a chronically relapsing condition for which there is no cure. Current treatment of CD involves the use of antibiotics, anti-inflammatories and immunosuppressants, but individuals with CD can still experience a life long battle with periods of exacerbation and remission, suggesting that the current therapy is inadequate. Several models for the treatment and prevention of $\mathrm{CD}$ are currently being examined. One of these new treatment approaches involves the administration of antiinflammatory cytokines of Th2 lineage directly to the affected intestine. Several investigators $(10,52)$ have suggested the use of site-directed IL adenovirus therapy; however, despite the promising results seen in animal models, there was little success in the few clinical trials performed to date $(15,65)$. The lack of effectiveness with this treatment may be attributed to inadequate transfer techniques. Furthermore, site-specific cytokine administration might not be the desired therapy because intraperitoneal injection of IL-4 was shown to exacerbate the development of colitis in the $\mathrm{CD} 4{ }^{+} \mathrm{CD} 45 \mathrm{RB}$ high $\mathrm{T}$ cell mouse model (66).

Therefore, a more effective treatment may be to systemically elevate the anti-inflammatory cytokines of Th2 origin, such as IL-10, using a route that circumvents the previous problems with delivery. This could be accomplished by using agents such as the Epstein-Barr virus, which is known to produce a homologue to IL-10 (29). The systemic distribution of IL-10 will antagonize the Th1 immune response, ultimately helping in the attenuation of the inflammation. In addition, local administration of the IL-10-producing bacteria Lactococcus lactis has also proven to be beneficial in the treatment of IBD in mice (50). Another potential therapy could involve the use of cytokine neutralizing antibodies, such as anti-IL-12, which has been shown to decrease inflammation in animal models $(26,66,67)$. Clearly, more research aimed at identifying molecular patterns on the parasites would prove beneficial, 
specifically if anti-inflammatory cytokines could be elevated without elevating the entire Th2 cytokine profile.

Nevertheless, the best possible goal is prevention from developing CD. Helminth infection not only alleviates the severity, but also prevents the occurrence of IBD in animals. The rationale for the use of helminths would be further supported through the identification of predisposing genes (such as the NOD2 mutants seen in humans [68]) in rodents; it will be interesting to determine if these mutants are more susceptible to colitis and then test the effects of helminth colonization. Genetic screening could identify individuals at risk for developing CD (such as those with NOD2 mutations) and helminth administration could be provided as an immunization. Clearly, the prospect of infecting humans with helminths is not going to be met with great enthusiasm, especially when offered as a means of preventative therapy. Therefore, additional research is necessary to identify the mechanism by which these parasites induce a Th2-mediated immune response. On identification of the Th2 reactive components involved, they could then be given to CD-stricken

\section{REFERENCES}

1. Shanahan F. Crohn's disease. Lancet 2002;359:62-9.

2. Berg DJ, Zhang J, Weinstock JV, et al. Rapid development of colitis in NSAID-treated IL-10-deficient mice. Gastroenterology 2002;123:1527-42.

3. Elliott DE, Urban JF Jr, Argo CK, Weinstock JV. Does the failure to acquire helminthic parasites predispose to Crohn's disease? FASEB J 2000;14:1848-55

4. Weinstock JV, Summers RW, Elliott DE, Qadir K, Urban JF Jr, Thompson R. The possible link between de-worming and the emergence of immunological disease. J Lab Clin Med 2002;139:334-8.

5. Elliott DE, Li J, Blum A, et al. Exposure to schistosome eggs protects mice from TNBS-induced colitis. Am J Physiol Gastrointest Liver Physiol 2003;284:G385-91.

6. Ekbom A, Wakefield AJ, Zack M, Adami HO. Perinatal measles infection and subsequent Crohn's disease. Lancet 1994;344:508-10.

7. Hugot JP, Alberti C, Berrebi D, Bingen E, Cezard JP. Crohn's disease: The cold chain hypothesis. Lancet 2003;362:2012-5.

8. Cashman KD, Shanahan F. Is nutrition an aetiological factor for inflammatory bowel disease? Eur J Gastroenterol Hepatol 2003; 15:607-13.

9. Husby S. Dietary antigens: Uptake and humoral immunity in man. APMIS Suppl 1988;1:1-40.

10. Madsen K. Combining T cells and IL-10: A new therapy for Crohn's disease? Gastroenterology 2002;123:2140-4

11. Yoshida T, Hachimura S, Kaminogawa S. The oral administration of low-dose antigen induces activation followed by tolerization, while high-dose antigen induces tolerance without activation. Clin Immunol Immunopathol 1997;82:207-15.

12. Mowat AM, Lamont AG, Bruce MG. A genetically determined lack of oral tolerance to ovalbumin is due to failure of the immune system to respond to intestinally derived tolerogen. Eur J Immunol 1987;17:1673-6.

13. Weiner HL. Oral tolerance: Immune mechanisms and the generation of Th3-type TGF-beta-secreting regulatory cells. Microbes Infect 2001;3:947-54.

14. MacDonald TT. Oral tolerance. Eating your way towards immunosuppression. Curr Biol 1994;4:178-81.

15. Rogy MA, Beinhauer BG, Reinisch W, Huang L, Pokieser P. Transfer of interleukin-4 and interleukin-10 in patients with severe inflammatory bowel disease of the rectum. Hum Gene Ther 2000;11:1731-41.

16. van Deventer SJ. Taming the mucosal immune response in Crohn's disease. Best Pract Res Clin Gastroenterol 2002;16:1035-43.

17. Shivananda S, Lennard-Jones J, Logan R, et al. Incidence of inflammatory bowel disease across Europe: Is there a difference between north and south? Results of the European Collaborative Study on Inflammatory Bowel Disease (EC-IBD). Gut 1996;39:690-7. individuals to dampen the inflammatory response or administered as a preventative immunization to the population at risk for developing $\mathrm{CD}$.

Recently, Elliott et al (5) showed that prior administration of dead schistosome eggs could alleviate TNBS-induced colitis in mice. Furthermore, in a pilot study (69), this group demonstrated the effectiveness of helminth exposure in treating human $\mathrm{CD}$. Combined, these results suggest that administration of these Th2-promoting agents or cytokines (such as IL-10) will prove beneficial in prevention and treatment of $\mathrm{CD}$, or in the maintenance of $\mathrm{CD}$ remission. While these future therapies seem quite distant from mainstream use for the treatment and prevention of human disease, they nevertheless represent exciting new avenues and possibilities for controlling CD as well as other chronic Th1-dominant inflammatory conditions, such as multiple sclerosis and rheumatoid arthritis.

ACKNOWLEDGEMENTS: We thank Dr M Ropeleski for stimulating criticism and A Lin for illustrations.

18. Sonnenberg A, Wasserman IH. Epidemiology of inflammatory bowel disease among U.S. military veterans. Gastroenterology 1991;101:122-30

19. MacDonald TT. Gastrointestinal inflammation. Inflammatory bowel disease in knockout mice. Curr Biol 1994;4:261-3.

20. Shapira M, Tamir A. Crohn's disease in the Kinneret sub-district, Israel, 1960-1990. Incidence and prevalence in different ethnic subgroups. Eur J Epidemiol 1994;10:231-3.

21. Tan CC, Kang JY, Guan R, Yap I, Tay HH. Inflammatory bowel disease: An uncommon problem in Singapore. J Gastroenterol Hepatol 1992;7:360-2

22. Sonnenberg A. Occupational distribution of inflammatory bowel disease among German employees. Gut 1990;31:1037-40.

23. Khan WI, Blennerhasset PA, Varghese AK, et al. Intestinal nematode infection ameliorates experimental colitis in mice. Infect Immun 2002;70:5931-7.

24. Kurata JH, Kantor-Fish S, Frankl H, Godby P, Vadheim CM. Crohn's disease among ethnic groups in a large health maintenance organization. Gastroenterology 1992;102:1940-8.

25. Bregenholt $\mathrm{S}$, Claesson MH. Increased intracellular Th1 cytokines in scid mice with inflammatory bowel disease. Eur J Immunol 1998;28:379-89.

26. Rogler G, Andus T. Cytokines in inflammatory bowel disease. World J Surg 1998;22:382-9.

27. Parronchi P, Romagnani P, Annunziato F, et al. Type 1 T-helper cell predominance and interleukin-12 expression in the gut of patients with Crohn's disease. Am J Pathol 1997;150:823-32.

28. Fuss IJ, Neurath M, Boirivant M, et al. Disparate CD4+ lamina propria (LP) lymphokine secretion profiles in inflammatory bowel disease. Crohn's disease LP cells manifest increased secretion of IFN-gamma, whereas ulcerative colitis LP cells manifest increased secretion of IL-5. J Immunol 1996;157:1261-70.

29. Goldsby RA, Kindt TJ, Osborne BA. Cytokines. Immunology 2000:317-26

30. Seder RA, Paul WE. Acquisition of lymphokine-producing phenotype by CD4+ T cells. Annu Rev Immunol 1994;12:635-73.

31. Mosmann TR, Cherwinski H, Bond MW, Giedlin MA, Coffman RL. Two types of murine helper T cell clone. I. Definition according to profiles of lymphokine activities and secreted proteins. J Immunol 1986;136:2348-57

32. Qadir K, Metwali A, Blum AM, Li J, Elliott DE, Weinstock JV. TGF-beta and IL-10 regulation of IFN-gamma produced in Th2-type schistosome granulomas requires IL-12. Am J Physiol Gastrointest Liver Physiol 2001;281:G940-6.

33. Trinchieri G, Scott P. Interleukin-12: Basic principles and clinical applications. Curr Top Microbiol Immunol 1999;238:57-78.

34. Kubin M, Chow JM, Trinchieri G. Differential regulation of interleukin-12 (IL-12), tumor necrosis factor alpha, and IL-1 beta production in human myeloid leukemia cell lines and peripheral blood mononuclear cells. Blood 1994;83:1847-55. 
35. Tozawa K, Hanai H, Sugimoto K, et al. Evidence for the critical role of interleukin-12 but not interferon-gamma in the pathogenesis of experimental colitis in mice. J Gastroenterol Hepatol 2003;18:578-87.

36. Khan WI, Vallance BA, Blennerhassett PA, et al. Critical role for signal transducer and activator of transcription factor 6 in mediating intestinal muscle hypercontractility and worm expulsion in Trichinella spiralis-infected mice. Infect Immun 2001;69:838-44.

37. Lederer JA, Perez VL, DesRoches L, Kim SM, Abbas AK, Lichtman AH. Cytokine transcriptional events during helper T cell subset differentiation. J Exp Med 1996;184:397-406.

38. Kuhn R, Lohler J, Rennick D, Rajewsky K, Muller W. Interleukin-10-deficient mice develop chronic enterocolitis. Cell 1993;75:263-74

39. de Waal MR, Yssel H, Roncarolo MG, Spits H, de Vries JE. Interleukin-10. Curr Opin Immunol 1992;4:314-20.

40. Ribbons KA, Thompson JH, Liu X, Pennline K, Clark DA, Miller MJ. Anti-inflammatory properties of interleukin-10 administration in hapten-induced colitis. Eur J Pharmacol $1997 ; 323: 245-54$

41. Lindsay JO, Hodgson HJ. Review article: The immunoregulatory cytokine interleukin-10 - a therapy for Crohn's disease? Aliment Pharmacol Ther 2001;15:1709-16.

42. Yamada Y, Marshall S, Specian RD, Grisham MB. A comparative analysis of two models of colitis in rats. Gastroenterology 1992;102:1524-34

43. Gajewski TF, Fitch FW. Anti-proliferative effect of IFN-gamma in immune regulation. I. IFN-gamma inhibits the proliferation of Th2 but not Th1 murine helper T lymphocyte clones. J Immunol 1988;140:4245-52.

44. de Waal MR, Figdor CG, Huijbens R, et al. Effects of IL-13 on phenotype, cytokine production, and cytotoxic function of human monocytes. Comparison with IL-4 and modulation by IFN-gamma or IL-10. J Immunol 1993;151:6370-81.

45. Fiorentino DF, Zlotnik A, Vieira P, et al. IL-10 acts on the antigenpresenting cell to inhibit cytokine production by Th1 cells. J Immunol 1991;146:3444-51.

46. Blumberg RS, Saubermann LJ, Strober W. Animal models of mucosal inflammation and their relation to human inflammatory bowel disease. Curr Opin Immunol 1999;11:648-56.

47. Ilan Y, Weksler-Zangen S, Ben Horin S, et al. Treatment of experimental colitis by oral tolerance induction: A central role for suppressor lymphocytes. Am J Gastroenterol 2000;95:966-73.

48. Elson CO, Sartor RB, Tennyson GS, Riddell RH. Experimental models of inflammatory bowel disease. Gastroenterology 1995;109:1344-67.

49. Barbara G, Xing Z, Hogaboam CM, Gauldie J, Collins SM. Interleukin 10 gene transfer prevents experimental colitis in rats. Gut 2000;46:344-9.

50. Steidler L, Hans W, Schotte L, et al. Treatment of murine colitis by Lactococcus lactis secreting interleukin-10. Science 2000;289:1352-5.

51. Fuss IJ, Marth T, Neurath MF, Pearlstein GR, Jain A, Strober W.
Anti-interleukin 12 treatment regulates apoptosis of Th1 T cells in experimental colitis in mice. Gastroenterology 1999;117:1078-88.

52. Hogaboam CM, Vallance BA, Kumar A, et al. Therapeutic effects of interleukin-4 gene transfer in experimental inflammatory bowel disease. J Clin Invest 1997;100:2766-76.

53. Roth MP, Petersen GM, McElree C, Vadheim CM, Panish JF, Rotter JI. Familial empiric risk estimates of inflammatory bowel disease in Ashkenazi Jews. Gastroenterology 1989;96:1016-20.

54. Akdis CA, Blesken T, Akdis M, Wuthrich B, Blaser K. Role of interleukin 10 in specific immunotherapy. J Clin Invest 1998;102:98-106.

55. Jarrett E, Mackenzie S, Bennich H. Parasite-induced 'nonspecific' $\mathrm{IgE}$ does not protect against allergic reactions. Nature 1980;283:302-4.

56. Larrick JW, Buckley CE III, Machamer CE, et al. Does hyperimmunoglobulinemia-E protect tropical populations from allergic disease? J Allergy Clin Immunol 1983;71:184-8.

57. Gern JE. Viral respiratory infection and the link to asthma. Pediatr Infect Dis J 2004;23:S78-86.

58. Gern JE, Busse WW. Relationship of viral infections to wheezing illnesses and asthma. Nat Rev Immunol 2002;2:132-8.

59. Masters S, Barrett-Connor E. Parasites and asthma - predictive or protective? Epidemiol Rev 1985;7:49-58.

60. Reardon C, Sanchez A, Hogaboam CM, McKay DM. Tapeworm infection reduces epithelial ion transport abnormalities in murine dextran sulfate sodium-induced colitis. Infect Immun 2001;69:4417-23.

61. Obermeier F, Dunger N, Deml L, Herfarth H, Scholmerich J, Falk W. CpG motifs of bacterial DNA exacerbate colitis of dextran sulfate sodium-treated mice. Eur J Immunol 2002;32:2084-92.

62. Haslam N, Mayberry JF, Hawthorne AB, Newcombe RG Holmes GK, Probert CS. Measles, month of birth and Crohn's disease. Gut 2000;47:801-3.

63. Pardi DS, Tremaine WJ, Sandborn WJ, Loftus EV Jr, Poland GA, Melton LJ III. Perinatal exposure to measles virus is not associated with the development of inflammatory bowel disease. Inflamm Bowel Dis 1999;5:104-6.

64. Lione A, Scialli AR. Perinatal exposure to measles virus and the risk of inflammatory bowel disease. Reprod Toxicol 1997;11:647-52.

65. Fedorak RN, Gangl A, Elson CO, et al. Recombinant human interleukin 10 in the treatment of patients with mild to moderately active Crohn's disease. The Interleukin 10 Inflammatory Bowel Disease Cooperative Study Group. Gastroenterology 2000;119:1473-82.

66. Fort M, Lesley R, Davidson N, et al. IL-4 exacerbates disease in a Th1 cell transfer model of colitis. J Immunol 2001;166:2793-800.

67. Ogata H, Hibi T. Cytokine and anti-cytokine therapies for inflammatory bowel disease. Curr Pharm Des 2003;9:1107-13.

68. Baburajan B, Parkes M. The genetics of inflammatory bowel disease. Hosp Med 2003;64:599-602.

69. Summers RW, Elliott DE, Qadir K, Urban JF Jr, Thompson R, Weinstock JV. Trichuris suis seems to be safe and possibly effective in the treatment of inflammatory bowel disease. Am J Gastroenterol 2003;98:2034-41. 




The Scientific World Journal


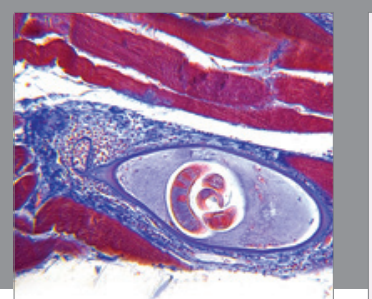

Gastroenterology Research and Practice



\section{Hindawi}

Submit your manuscripts at

http://www.hindawi.com



Disease Markers
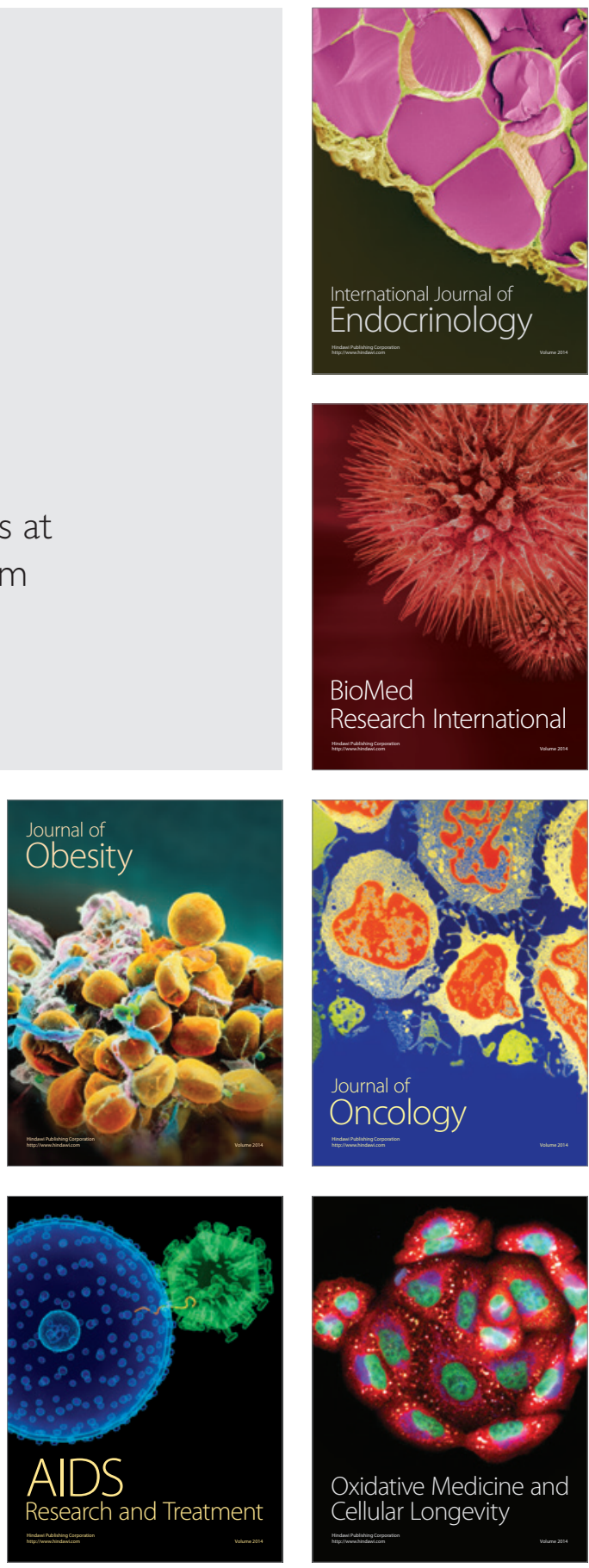